\title{
Proposal for Need Analysis in an Exam Preparation Course: A Descriptive Study
}

\author{
Cristian Alexander Chiroque Chero ${ }^{1}$ \\ ${ }^{1}$ Centre of Languages, Universidad de Piura, Piura, Peru \\ Correspondence: Cristian Alexander Chiroque Chero, Av. Ramón Mugica 131, Piura, Peru 20009.
}

Received: November 20, 2021

Accepted: December 23, 2021

Online Published: December 27, 2021

doi: $10.5539 /$ elt.v15n1p144

URL: https://doi.org/10.5539/elt.v15n1p144

\begin{abstract}
Need analysis is an essential element in the process of designing any language course as it seeks to cater for what learners need in their lessons. This study proposes a framework to analyse learners' needs for exam preparation courses. The proposed framework adopts the works of Macalister, Nation, and Brindley to address different linguistic and non-linguistic needs. To the best of the researcher's knowledge, no framework has ever been provided for teachers to carry out need analysis in the context of preparing for international exams. In this study, therefore, the framework was applied to find learners' needs in an exam preparation course for an A2 English level international exam. The participants were 10 learners aged 10-12 enrolled on a course in a private language centre. The data were collected through a combination of quantitative and qualitative tools, that is to say, by questionnaires, tests, and classroom observations. Results revealed that the framework herein proposed gives a detailed understanding of the learners' needs prior to the course showing that learners from this study have difficulties in the skills of reading, writing, and listening. Findings also revealed learners' preference for a variety of classroom activities, online games, and art-crafts.
\end{abstract}

Keywords: need analysis, EFL, learning needs, course design

\section{Introduction}

Need Analysis (NA) is a key element in the design of a language course and its effectiveness results in students' linguistic and non-linguistic needs being met. The importance of carrying out NA not only lies in the selection of course content and activities but also in the assessment of learners' progress and course evaluation. Graves (2000) states that it is the starting point for the design of a course and that the information from NA can be used to determine course objectives, content, activities, and assessment.

Over the last 20 years, the focus of NA has been mainly on English for Specific Purposes and English for Academic Purposes (Eshtehardi, 2017; Hutchinson and Waters, 1997; Nimasari, 2018; Sukarni, 2019) with scarce research on designing NA for exam preparation courses. This results in teachers having no guidelines or frameworks on how to carry out NA for exam preparation courses and they might tend to believe that for such courses, following a coursebook is the only way to deliver lessons. Thus, this research seeks to close this gap by proving a comprehensive way of carrying out NA and proposing a framework for the teachers' use.

\subsection{Research Questions}

This study seeks to answer the following research questions:

1) What would a Need Analysis framework be for exam preparation courses?

2) What are the needs of learners in terms of 'Necessities', 'Wants', and 'Lacks' in an A2 exam preparation course?

\subsection{Research Objectives}

The objectives expected to be achieved by this study are:

1) To propose a framework to carry out Need Analysis in an exam preparation course.

2) To identify the different types of needs of learners enrolling in an exam preparation course.

The present study will serve as a guide for teachers, syllabus designers, and coordinators to determine what students need in an exam preparation course and plan courses in line with learners' needs in mind. 
The need to carry out this research stems from the fact that even though the literature of need analysis provides important principles and procedures to determine learners' needs, a practical framework for applying these principles in carrying out need analysis for exam preparation courses is needed. Thus, a framework has been proposed here to determine learners' need enrolled on an exam preparation course.

\subsection{Previous Studies}

Given that NA has been the focus of English for Specific Purposes courses, there is scarce research on need analysis for exam preparation courses. Yet, some studies could offer insight into how these courses have carried out NA in their contexts. Alqunayeer and Zamir (2016) analysed the needs of female learners enrolled in an EFL university course using Hutchinson's and Waters' (1997) model of NA. They found that learners' need focused on speaking skills as well as on communicative activities with real-life tasks. In the same vein, Avgerou (2016) explored the needs of junior high school learners using a self-made questionnaire with the purpose of identifying learners' wishes, objective needs, and subjective needs. The results showed that learners wanted to use English for real-life situations, and there seemed to be two trends regarding instruction: a utilitarian view of English language learning and a communicative one. Likewise, Kaewpet (2009) proposed a framework for investigating learners' needs in an English for Specific Purposes context which extended into curriculum development, since the development of the framework began with an analysis of learning and communication needs for a group of learners and moved on to the implementation of it in a whole programme.

\section{Literature Review}

\subsection{Defining Needs and Need Analysis (NA)}

According to Richards (2001), needs can be defined as both objective and constructed reality. Objectively, they refer to what learners require in order to function effectively in a certain context. As a constructed reality, needs depend on the judgements and interests of teachers, learners, parents, and other stakeholders.

Numerous researchers have attempted to define the concept of NA from different perspectives. Pratt (1980) defines it as the process in which different procedures are used to identify and prioritise needs, which once identified, can be transformed into objectives. Similarly, Brindley (1989) states that NA refers to the identification of wants, desires, demands, expectations, motivations, lacks and requirements of learners taking part in a course. Likewise, Graves (2000) emphasises that it is a systematic and ongoing process around determining what students need and prefer, interpreting the information, and making decisions accordingly. Graves also suggests that it is necessary to gather information about the current state of learners in terms of language ability, goals, preferences and what they want to achieve. Overall, the process of NA involves collecting information about what learners need from a course, their preferences, lacks, and goals in order to make decisions for the design of any course.

\subsection{The Frameworks for $N A$}

Different models have been proposed in order to identify learners' various needs (Hutshinson \& Waters, 1987; Yalden, 1997; Brindley, 1989). Most of them address the different types of needs and offer ways to determine what learners need by focusing solely on objective needs. However, in this article, two models have been selected to discuss because they provide a comprehensive way of analysing learners' needs and include all the relevant needs addressed in other frameworks. Macalister and Nation (2010) divide needs into three categories: necessities, lacks and wants. Necessities refer to what is necessary for learners in terms of language use for a particular purpose. Lacks pertain to what learners need to improve their current language ability. Wants refer to what learners wish to learn and how they want to learn. Brindley (1989) divides the needs into two types: objective needs and subjective needs. The former include facts about who the learners are, their language skills, and what they need the language for. The latter include information about expectations, and attitudes that learners have about what and how they want to learn.

\subsection{The Methodology of NA}

As NA is similar to conducting a research project, it is necessary to consider questions whose answers are a prerequisite to identify the appropriate methodology (West, 1994). The what and why questions provide a guide as to the types of needs that can be identified and their usefulness in identifying learners' needs. Hutchinson and Waters (1987) offer a useful classification of needs: necessities, lacks, and wants. The when question seeks to determine at what point in the course NA should be carried out: before, at the start, or during the course. West (1994) suggests that it should be an ongoing process so that learners can reformulate their needs periodically. Long (2005) also points out that learners often find it difficult to articulate their needs in the initial stage of the course, and therefore ongoing NA is necessary. The who question refers to who is in charge of deciding what 
language needs are. West (1994) states that there are three main parties involved: the teachers, the students, and the company or other sponsor. The final question to be considered is the how, which refers to the selection of the instruments to gather information. Berwick (1989) makes a distinction between inductive and deductive methods. For example, inductive methods involve classroom observations and case studies, while deductive methods involve questionnaires and surveys. Long (2005) highlights the need to employ multiple tools because they add breadth and depth to the analysis and offer an important means of validating what has been found, thus meaning that both quantitative and qualitative instruments need to be used when carrying out NA.

\subsection{The Design of NA}

Richards (2001) states that, in order to carry out NA, teachers need to decide on the practical procedures involved in collecting, organising, analysing and reporting the information. Furthermore, there should be clear reasons for collecting the different kinds of information so as not to produce information overload. In that way, it is important to have a clear picture of how to carry out NA in clear stages. Graves (2000) proposes the following steps which are cyclical in nature:

a. Deciding what information to gather and why.

b. Deciding the best way to gather, when and how and from whom.

c. Gathering the information.

d. Interpreting the information.

e. Acting on the information.

f. Evaluate the effect of the action.

\subsection{Exam Preparation Courses}

Although an exam preparation class has many aspects in common with a general language class, there are some relevant features of exam preparation classes as suggested by Burgess and Head (2005):

a. Learners' expectations are high.

b. All learners have the same specific goal although the purpose for reaching such a goal can vary.

c. Learners are more prone to stress and anxiety.

d. Learners need variety in the course.

e. Teachers do not have complete flexibility in the course content.

f. Emphasis on some specific skills and systems is crucial.

Burguess and Head (2005) also state that careful planning for an exam course is necessary to ensure that students are prepared to perform their best when facing an exam. Therefore, the course needs to be carefully planned in advance to ensure proper coverage of various exam tasks, as well as language content.

In terms of NA, learners' necessities are decided by what the exam covers in terms of language skills, grammar, and vocabulary. Thus, it is easy to carry out NA for exam preparation courses taking into account what the specific exam covers with regard to language content. However, learners should also express what they feel they need. In this way, proper NA should balance information about learners and teachers to create what is often called a defensible curriculum (Brown, 2009).

\section{Method}

This study uses a mixed methodology, that is, both quantitative and qualitative data are collected and analysed to determine learners' needs on an exam preparation course. A triangulation methodology is therefore used; in other words, different sets and sources of data are compared with one another (Brown, 2009). In addition, considering the view of Huberman and Miles (1994), specifically that "different perspectives, sources, data types, etc. must be carefully thought through and planned so that they cross-validate each other" (p. 438), an appropriate sequence is followed so that two or more procedures can produce better information.

\subsection{Participants}

The participants in this study were 10 young Peruvian learners aged 11-12 enrolled on a course preparing for the international exam Cambridge A2 YLE Flyers (A2 level according to the Common European Framework of Reference). Table 1 shows the details of the participants. 
Table 1. Participants

\begin{tabular}{ll}
\hline & Number of students \\
\hline Age & 11 years old (7 students) \\
& 12 years old (3 students) \\
Gender & Male (7 students) \\
& Female (3 students) \\
Prior language experience & All have successfully completed an A1+ General English course \\
\hline
\end{tabular}

\subsection{Research Design}

The design of NA has been adapted from Macalister and Nation (2010), and Brindley (1989). The proposal for carrying out NA is detailed in Table 2 .

Table 2. Proposal for the design of NA

\begin{tabular}{llll}
\hline & Necessities & Lacks & Wants \\
\hline Subjective information & N1 & L1 & x \\
Objective information & N2 & L2 & W1 \\
\hline
\end{tabular}

The proposal from Table 2 takes into account the different categories proposed by the two aforementioned authors, that is, subjective needs, objective needs, needs, lacks, and wants. This combination gives rise to five categories of needs which can be addressed in the process of gathering information for NA: subjective necessities (N1), objective necessities (N2), subjective lacks (L1), objective lacks (L2), and subjective wants (W1). As wants are subjective per se, objective wants are not considered. It is hoped that these categories will give a comprehensive perspective on what learners need from a course. Additionally, these categories also allow the participation of teachers and students alike, as suggested by Brown (2009).

These five types of needs refer to the what question stated in the literature review. The next table shows how the other questions are addressed in order to determine the correct methodology for each need.

Table 3. Framework for NA for the exam preparation course

\begin{tabular}{|c|c|c|c|c|}
\hline What & Why & When & How & By whom \\
\hline N1 & To find out learners' own needs & Before the course & Close ended Questionnaire & Learners \\
\hline $\mathrm{N} 2$ & $\begin{array}{l}\text { To find out what learners need } \\
\text { for their exam }\end{array}$ & Before the course & $\begin{array}{l}\text { An analysis of the Teacher's } \\
\text { Exam Handbook }\end{array}$ & Teacher \\
\hline L1 & $\begin{array}{l}\text { To find learners' perceived } \\
\text { difficulties }\end{array}$ & $\begin{array}{l}\text { At the beginning and } \\
\text { during the course }\end{array}$ & $\begin{array}{l}\text { A self-rating chart and } \\
\text { open-ended survey }\end{array}$ & Learners \\
\hline L2 & $\begin{array}{l}\text { To find out what learners } \\
\text { actually struggle with }\end{array}$ & $\begin{array}{l}\text { At the beginning and } \\
\text { during the course }\end{array}$ & $\begin{array}{l}\text { Diagnostic assessment: Test } \\
\text { and observation }\end{array}$ & Learners \\
\hline W1 & $\begin{array}{l}\text { To find out learners' preferred } \\
\text { activities and grouping }\end{array}$ & $\begin{array}{l}\text { Before the course and } \\
\text { during the course }\end{array}$ & A close-ended survey & Learners \\
\hline
\end{tabular}

Table 3 details the different questions that need to be addressed for each need. The purpose of $\mathrm{N} 1$ is to identify the learners' perceived needs before the course through a close-ended questionnaire. N2 seeks to identify what skills and subskills learners need objectively for the target exam and it is identified prior to the course through an analysis of the Teachers' Exam Handbook carried out by the teacher. This is a resource for teachers which sets out the skills and subskills tested in the A2 Flyers exam. L1 seeks to identify learners' subjective difficulties in their language skills through a self-rating chart and an open-ended survey at the beginning of the course. L2 also aims to identify learners' difficulties, albeit in an objective way through a diagnostic assessment carried out at the beginning of the course. This is a type of need that should also be addressed during the course by means of progress tests. W1 seeks to identify learners' preferred activities and ways of working through a close-ended survey before the course. This is also a type of need addressed during the course through classroom discussions.

\subsection{Instruments}

Three instruments were chosen to carry out comprehensive NA for the learners enrolled on the course. The self-made questionnaire contained three sections which addressed N1, L1 and W1. With regard to validity, two colleagues reviewed the questionnaire to ensure that items gathered the information needed and suggested different changes to the instrument. Diagnostic assessment was also used during the first two days of the course to address L2. The diagnostic assessment consisted of a test containing five sections based on the skills outlined in the Teacher's Exam Handbook: reading, writing, listening, grammar and vocabulary, and two classroom 
observations in which the researcher set up two speaking activities to assess learners' speaking skills and pronunciation. The test was validated by two colleagues who reviewed each section to ensure that each part balanced the aspects of reliability, validity, and practicality. Finally, a self-made chart was designed to address $\mathrm{N} 2$, in which the different skills and subskills needed for the learners' exam were systematised.

\subsection{Procedures}

Grave's (2000) sequence of NA was followed in that the different aspects of NA were decided. After students enrolled on the exam preparation course, the teacher carried out the analysis of the Teachers' Exam Handbook in order to determine the skills and subskills needed for the target exam, and in that way addressed N2. A week prior to the beginning of the course, students were invited to an online session in order to complete the questionnaire addressing N1, L1, and W1. They were asked to do so in a noiseless environment and under the supervision of the teacher in case something was not clear. The first three days were introductory sessions in which students completed the diagnostic test and two speaking activities in order to address L2. Subsequently, the data were interpreted, and the course was designed with those findings in mind, prioritising different language systems and skills.

\section{Results and Discussion}

\subsection{Research Question 1}

The framework proposed to carry out NA during exam preparation courses derives from the works of Macalister and Nation (2010), and Brindley (1989), and is set out in Table 2 above. The detailed use of such a framework for the current study is presented in Table 3, in which the NA questions are addressed together with the chosen instruments and the sources from which different types of information can be obtained. Not only does this framework aim to identify different types of needs thoroughly, but it also gives a comprehensive view of what needs to be considered when designing an exam preparation course.

\subsection{Research Question 2}

This question is addressed by identifying learners' needs with the proposed framework, and therefore using different quantitative and qualitative instruments. The three instruments were a questionnaire, a diagnostic test, and the teachers' exam handbook, while the results are discussed according to the types of needs. As this a descriptive study, the results are presented in terms of percentages and frequencies for each need. Furthermore, some implications for the design of the course are discussed at the end of this section. The items of the questionnaire were analysed using Simple Frequency Distribution Method. The researcher used SPSS 23 for analysing the responses, while the diagnostic test was analysed through the basic descriptive statistics, and the teacher's analysis of the handbook was analysed through descriptive analysis of the skills and subskills contained in the Teachers' Exam Handbook.

\section{Subjective Needs (N1)}

These types of needs were identified in the first section of the questionnaire administered to the learners prior to the beginning of the course. Learners were given a question with different options they could choose from, and a space at the end for any optional reason. Table 4 shows the results of this section.

Table 4. Descriptive statistics of the first type of need

\begin{tabular}{lll}
\hline Why do you want to prepare for the A2 Flyers exam? & Frequency & Percentage \\
\hline To get a language certificate & 7 & $70 \%$ \\
To measure my progress in English & 8 & $80 \%$ \\
To be able to communicate with foreigners & 3 & $30 \%$ \\
Because I will use English in the future & 5 & $50 \%$ \\
Because I like English & 8 & $80 \%$ \\
To understand songs and videos in English & 4 & $40 \%$ \\
Because my friends will prepare too & 7 & $70 \%$ \\
Because my parents want me to prepare for the exam & 4 & $40 \%$ \\
Because my friends go to this language centre too. & 6 & $60 \%$ \\
Have you taken any Cambridge Exam before? & & \\
Yes & 6 & $60 \%$ \\
No & 4 & $40 \%$ \\
\hline
\end{tabular}


The results showed that most learners enrolled on the exam preparation course because they wanted to measure how well they were progressing in their language development and because they enjoyed learning English. Notably, some of them also showed an extrinsic reason for taking this course, namely, to obtain a certificate and because their friends take the course too. Moreover, almost half of the learners admitted that they had not taken a Cambridge Exam before, which affected the design of the course when it came to familiarising learners with the exam format. This indicated that students had both intrinsic and extrinsic reasons for taking this course.

\section{Objective Needs (N2)}

Prior to the course, the researcher analysed the Teachers' Exam Handbook. This is a resource available for teachers which sets out the skills and subskills tested in the A2 Flyers exam; it details the task type, the number of questions, and the procedures for each part of the exam. The results are shown in the next table.

Table 5. Systematic analysis of the Teachers' Exam Booklet to address N2

\begin{tabular}{|c|c|c|c|}
\hline \multirow{3}{*}{$\begin{array}{l} \\
\text { Objective Needs: } \\
\text { Skills and subskills }\end{array}$} & \multicolumn{3}{|c|}{ Teacher's analysis of the Exam Handbook } \\
\hline & Skills & Subskills to work on & Exam tasks \\
\hline & Reading & Understanding functional language & Part 2 \\
\hline & Writing & Understanding and using grammar and vocabulary in context & Part $4,6,7$ \\
\hline & & Using basic cohesive devices & Part 7 \\
\hline & & Finding synonyms and paraphrasing & Part 5 \\
\hline & & Reading for details and gist & Part 3 \\
\hline & Listening & Listening for descriptions. & Part 1,2 \\
\hline & & Listening for specific information. & Part $4,5,3$ \\
\hline & Speaking & Using appropriate intonation and correct pronunciation. & All \\
\hline & & Responding and forming questions & Part 1,2 \\
\hline & & Describing an event using simple linkers & Part 3, 4 \\
\hline & & $\begin{array}{l}\text { Responding to personal questions using correct grammar and } \\
\text { vocabulary }\end{array}$ & Part 4 \\
\hline
\end{tabular}

The results from this chart showed what learners objectively needed to be prepared for in the target exam in terms of the different skills and subskills. The findings also illustrated that each skill has specific subskills which are tested in the different parts of the exam. Moreover, these results highlighted that each subskill can be assessed in more than one exam task. This implied that much work was needed for the development of subskills and that after these had been developed, learners could focus on exam tasks. The priorities of the skills were determined after the results of the diagnostic assessment.

\section{Subjective Lacks (L1)}

This type of need was identified through a self-rating chart and an open-ended survey. The students were shown the different skills and systems necessary for the exam and were given four-scale items: weak, satisfactory, good, and excellent. For each section, they had to choose one of such options. Table 6 shows the results of this need.

Table 6. Descriptive statistics of the self-rating chart

\begin{tabular}{lllll}
\hline How do you rate your skills in these areas? & Weak & Satisfactory & Good & Excellent \\
\hline Listening & $3(30 \%)$ & $7(70 \%)$ & & \\
Writing & $2(20 \%)$ & $3(30 \%)$ & $5(50 \%)$ & \\
Speaking & & $4(40 \%)$ & $6(60 \%)$ & \\
Grammar & & $4(40 \%)$ & $4(40 \%)$ & $2(20 \%)$ \\
Vocabulary & & $4(40 \%)$ & $2(20 \%)$ & $4(40 \%)$ \\
Reading & $3(30 \%)$ & $6(60 \%)$ & $4(40 \%)$ & $4(40 \%)$ \\
Pronunciation & & & $10(10 \%)$ & \\
\hline
\end{tabular}

The results indicated that learners' perceived lacks were listening, pronunciation, grammar, and vocabulary. Learners also signalled that their strongest skills were reading and speaking. These results complemented the 
open-ended survey in which learners were given the opportunity to express their views in a less controlled way. The data were analysed through categorisation of the different skills that learners indicated in each of their responses. Table 7 shows a sample of this:

Table 7. Sample of qualitative results of student's open-ended survey

\begin{tabular}{ll}
\hline Question & Learner's written responses \\
\hline & Student 1: Writing because I make a lot of mistakes quite often. [Writing skills] \\
& Student 2: For me, grammar is difficult because sometimes I don't remember the \\
Which skill are the most & rules. [grammar] \\
difficult for you and why? & $\begin{array}{l}\text { Student 3: For me, listening is very difficult because sometimes there are words I } \\
\text { don't understand and because of the high speed of the recording. [Listening] }\end{array}$ \\
& $\begin{array}{l}\text { Student 4: For me, listening and pronunciation are difficult because I don't know } \\
\text { how to say some words and I don't understand them. [Listening and } \\
\text { pronunciation] }\end{array}$
\end{tabular}

The results in Table 6 confirmed that learners perceived their difficulties as mainly lying in listening, grammar, pronunciation and writing skills. These findings were compared with those of the diagnostic assessment which showed what learners lacked objectively.

Objective Lacks (L2)

This need was identified through two tools: a written diagnostic test and a classroom observation carried out during the first introductory week of the course. First, the test was administered based on the skills analysed in the Teacher's Exam Handbook, each section carried 20 marks. In the other session, two speaking tasks were set up for learners to talk about certain topics. The researcher took notes on their strengths and weaknesses in terms of pronunciation (individual sounds, stress, and intonation) and speaking skills (appropriate grammar and vocabulary, interaction, and conveyance of ideas). Tables 8 and 9 indicate the mean for each section of the exam.

Table 8. Descriptive statistics of the Written Diagnostic Test

\begin{tabular}{lll}
\hline Language areas & Number of points per section & Mean \\
\hline Reading & 20 & 12.11 \\
Writing & 20 & 14.4 \\
Listening & 20 & 11.25 \\
Grammar & 20 & 16.3 \\
Vocabulary & 20 & 16.4 \\
\hline
\end{tabular}

Table 9. Descriptive results of the classroom observation

\begin{tabular}{|c|c|c|}
\hline Classroom observation & Strengths & Weaknesses \\
\hline \multirow[t]{2}{*}{ Pronunciation } & $\begin{array}{l}\text { - Individual sounds and vowels: } \\
/ \mathrm{u}: /, / \mathrm{t} /, / \mathrm{e} /, / \mathrm{i}: /, / \mathrm{a} /\end{array}$ & $\begin{array}{l}\text { - Difficulties in individual } \\
\text { sounds: } / 3: /, / \mathrm{s}: /, / \theta /\end{array}$ \\
\hline & $\begin{array}{l}\text { - Good stress at word level. The } \\
\text { schwa sound is not stressed. }\end{array}$ & $\begin{array}{l}\text { - Lack of intonation in } \\
\text { questions. }\end{array}$ \\
\hline \multirow[t]{2}{*}{ Speaking } & $\begin{array}{l}\text { - Use of appropriate basic linkers } \\
\text { such as and, or, but }\end{array}$ & $\begin{array}{l}\text { - Subject- verb agreement e.g., } \\
\text { she like go shopping. }\end{array}$ \\
\hline & $\begin{array}{l}\text { - Messages are clearly conveyed } \\
\text { and interaction is effective }\end{array}$ & $\begin{array}{l}\text { - Some incorrect collocations } \\
\text { e.g., go to home, pass time. }\end{array}$ \\
\hline
\end{tabular}

The results signalled that the skills in need of improvement were listening, writing, and reading. The latter contrasted with what learners stated in their subjective lacks, in which they indicated that reading was one of their strong skills. As for the classroom observations, it was evident that students needed to work on their pronunciation and review some grammar and vocabulary items. This coincided with the results from the self-rating chart, which showed that grammar was a strong domain for the learners. Therefore, decisions were made as to what to include and prioritise on the exam preparation course. 


\section{Subjective Wants (W1)}

The results for this type of need were identified through Section 3 in the questionnaire. There were two categories in this section: ways of working, and preferred learning activities. Table 10 shows the results of this type of need.

Table 10. Descriptive statistics of section III in the questionnaire

\begin{tabular}{llll}
\hline In class I like & Yes & A little & No \\
\hline Working individually & $6(60 \%)$ & $3(30 \%)$ & $1(10 \%)$ \\
Working in pairs & $8(80 \%)$ & $1(10 \%)$ & $1(10 \%)$ \\
Working in small groups & $8(80 \%)$ & $1(10 \%)$ & $1(10 \%)$ \\
My preferred learning activities & Frequency & Percentage \\
In class, I like playing online games. & 10 & $100 \%$ \\
In class, I like learning by using pictures and videos & 10 & $100 \%$ \\
In class, I like learning talking with classmates & 8 & $80 \%$ \\
I like writing in online boards & 8 & $80 \%$ \\
I like discovering things on my own & 8 & $80 \%$ \\
I like the teacher to give us problems to work on & 5 & $50 \%$ \\
I like learning by using English in conversations & 8 & $80 \%$ \\
I like the teacher to explain everything to us. & 8 & $80 \%$ \\
I like writing in my book & 5 & $50 \%$ \\
I like learning English by reading magazines, books, blogs. & 8 & $80 \%$ \\
I like to practise by repeating what I hear. & 6 & $60 \%$ \\
I like doing art crafts. & 10 & $100 \%$
\end{tabular}

The findings illustrated that learners needed variety when it came to grouping. They mostly preferred working in pairs and in groups and sometimes working individually which was an important element for collaborative learning. As for the learners' preferred activities, the results indicated that they expected a wide array of classroom activities such as online games, videos and pictures, and art-crafts.

\subsection{Implications for the Course Design}

The results of N1, N2, L1, L2 and W2 showed that learners had specific needs in mind when it came to preparing for an exam, which had to be addressed. Moreover, there were some discrepancies between what learners felt and what they needed objectively. For example, while learners reported reading as a strong area, the diagnostic assessment indicated that it was actually a weakness. As Graves (2000) suggests, once the information has been gathered, decisions need to be made for the course design. Therefore, given the amount of information obtained, the researcher decided to prioritise some linguistic needs during the course as well as some non-linguistic needs. Table 11 shows the linguistic and non-linguistic needs prioritised.

Table 11. Priorities from the NA data collection

\begin{tabular}{ll}
\hline Linguistic needs & Evidence from NA \\
\hline Reading & L2 and L1 results \\
Listening & L1 and L2 results \\
Pronunciation & L1 and L2 results \\
Speaking & L2 results \\
Revision of grammar, vocabulary, and writing & L1 and L2 \\
Non-linguistic needs & \\
Variety of ways of working & W1 \\
Variety of classroom activities & W2 \\
Foster learners' intrinsic needs by making them aware of their progress & N1 \\
\hline
\end{tabular}


In order to prioritise the language areas, time constraints were also taken into consideration. The course consisted of 12 hours of lessons per week for one month, adding up to 48 hours. Therefore, the course covered the language areas that were prioritised: reading, listening, pronunciation and speaking skills, in that specific lessons were devoted to developing these skills. Constant revision and recycling of grammar and vocabulary were also emphasised given the findings from the speaking classroom observations which may have a positive effect on the development of the language skills. As for the non-linguistic needs, during the course, learners worked with a variety of classroom activities especially those chosen in the questionnaire. Additionally, in order to cater for N1, students, during the course, were given a sense of progress in their language skills through self-assessment and reflection on their skills.

As NA is also an ongoing process, L1, L2 and W1 were revised during the lesson. After each unit, students were given a self-rating survey to identify their subjective lacks; the progress tests after every two units were also used to determine the progress which learners had made and those areas that needed improvement. Finally, as for learners' subjective wants, classroom discussions were carried out after every other unit so as to suggest any change in the different learning activities.

\section{Conclusion}

This article reported the results of a small-scale study of NA conducted with only 10 learners. A large-scale investigation with different classes and groups of learners may yield more insightful results. Although this study used a variety of sources and methods, such as questionnaires, observations, and self-reports, perhaps more qualitative tools could be employed to enrich the data.

Furthermore, some guidelines could be given for those who carry out NA for exam preparation courses. First, it is important to draw on different tools to gather information about learners. More importantly, however, is to determine how such information can be used to address different needs. Second, the requirements of a particular exam, that is, the different skills and subskills must be regarded as objective needs because they involve what learners need to perform in an examination. Third, time constraints also constitute an important factor for the design of a course because they determine how much time is available to cover the different language areas and exam tasks. For instance, when there is not enough time between the exam and the preparation, more emphasis could be placed on very specific language skills that need improvement, with a focus on exam tasks. Fourth, it is recommended that teachers avoid being overwhelmed by the amount of information collected in NA. Thus, they should scrutinise the information carefully in order to determine the implications for the course design.

This research proposes a NA Framework for exam preparation courses drawing on the works of Macalister and Nation (2010) and Brindley (1989). This framework addresses different types of needs in a thorough way and was also used to respond to the second research question, which sought to identify learners' needs in terms of necessities, lacks and wants. The use of the proposed framework resulted in a detailed collection of data addressing different needs from which the researchers could make informed decisions about what to include in the design of the course. The results of the NA showed that, although in exam classes, learners' needs are determined by what they need to pass an exam, they do have specific needs that must be considered when planning a course. Even if sometimes there are discrepancies among the findings, these should be carefully analysed to determine the possible implications for the course. Furthermore, objective and subjective information is necessary to make informed decisions as to what to prioritise on a course. This research hopes to pave the way for EFL teachers across the globe to use the proposed framework when carrying out NA for exam preparation courses, and thus cater for learners' needs in the classroom.

\section{References}

Alqunayeer, H. S., \& Zamir, S. (2016). Needs Analysis of Saudi EFL Female Students: A Case Study of Qassim University. Journal of Curriculum and Teaching, 5(1), 87-104. https://doi.org/10.5430/jct.v5n1p87

Avgerou, E. (2016). Needs analysis of the students of the 3d class of Junior High School. English Linguistics Research, 5(2), 45-56. https://doi.org/10.5430/elr.v5n2p45

Brindley, G. (1989). The role of needs analysis in adult ESL programme design. In R. Johnson (Ed.), The Second Language Curriculum (pp. 35-70). Cambridge: Cambridge University Press. https://doi.org/10.1017/CBO9781139524520.007

Brown, J. D. (2009). Foreign and second language needs analysis. In M. Long \& C. Doughty (Eds.), The Handbook of language teaching (pp. 269-293). Malden, MA: Wiley-Blackwell.

Burgess, S., \& Head, K. (2005). How to teach for exams. Longman: London. 
Eshtehardi, R. (2017). Needs Analysis and Course Design; A Framework for Designing Exam Courses. International Journal of Applied Linguistics and English Literature, 6(6), 274-288. https://doi.org/10.7575/aiac.ijalel.v.6n.6p.274

Graves, K. (2000). Designing language courses. Boston: Heinle and Heinle Publishers.

Huberman, A. M., \& Miles, M. B. (1994). Data management and analysis methods. In N. K. Denzin \& Y. S. Lincoln (Eds.), Handbook of qualitative research (pp. 428-444). Thousand Oaks, CA: Sage.

Hutchinson, T., \& Waters, A. (1987). English for specific purposes: A learning-centered approach. Cambridge: Cambridge University Press. https://doi.org/10.1017/CBO9780511733031

Kaewpet, C. (2009). A framework for investigating learner needs: Needs analysis extended to curriculum development. Electronic journal of foreign language teaching, 6(2), 209-220.

Long, M. (2005). Second language needs analysis. Cambridge University Press. https://doi.org/10.1017/CBO9780511667299

Macalister, J., \& Nation, I. S. P. (2010). Language curriculum design. London: ISP Nation. https://doi.org/10.4324/9780203870730

Nimasari, E. P. (2018). An ESP needs analysis: Addressing the needs of English for informatics engineering. Journal of English Educators Society, 3(1), 23-40. https://doi.org/10.21070/jees.v3i1.1085

Pratt, D. (1980). Curriculum design and development. New York: Harcourt Brace.

Richards, J. C. (2001). Curriculum development in language teaching. Cambridge: Cambridge University Press. https://doi.org/10.1017/CBO9780511667220

Sukarni, S. (2019). A need analysis for ESP-content materials for accountancy programme at vocational high school. In Proceedings of the 3rd English Language and Literature International Conference (pp. 144-151). https://doi.org/10.4108/eai.27-4-2019.2285343

West, R. (1994). Needs analysis in language teaching. Language teaching, 27(1), 1-19. https://doi.org/10.1017/S0261444800007527

Yalden, J. (1987). Principles of Course Design for Language Teaching. Cambridge: Cambridge University Press.

\section{Copyrights}

Copyright for this article is retained by the author(s), with first publication rights granted to the journal.

This is an open-access article distributed under the terms and conditions of the Creative Commons Attribution license (http://creativecommons.org/licenses/by/4.0/). 